\title{
CD90 affects the biological behavior and energy metabolism level of gastric cancer cells by targeting the PI3K/AKT/HIF-1 $\alpha$ signaling pathway
}

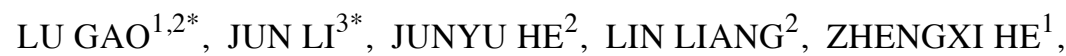 \\ CHUNXUE YUE ${ }^{2}$, XI JIN ${ }^{2}$, GENGQIU LUO ${ }^{4}$ and YANHONG ZHOU ${ }^{1,2}$ \\ ${ }^{1}$ NHC Key Laboratory of Carcinogenesis, Hunan Cancer Hospital and The Affiliated Cancer Hospital of \\ Xiangya School of Medicine, Central South University, Changsha, Hunan 410013; ${ }^{2}$ Cancer Research Institute, \\ Basic School of Medicine, Central South University, Changsha, Hunan 410078; \\ ${ }^{3}$ Department of Nursing, Xiangya Hospital, Central South University; ${ }^{4}$ Department of Pathology, Xiangya Hospital, \\ Basic School of Medicine, Central South University, Changsha, Hunan 410008, P.R. China
}

Received December 4, 2019; Accepted September 8, 2020

DOI: $10.3892 / \mathrm{ol} .2021 .12451$

\begin{abstract}
CD90, also known as Thy-1 cell surface antigen, is located on human chromosome 11q23.3, and encodes a glycosylphosphatidylinositol-linked cell surface glycoprotein. CD90 serves a key role in malignancy by regulating cell proliferation, metastasis and angiogenesis. Gastric cancer is one of the most common types of malignancy. Patients with advanced gastric cancer have a poor prognosis. CD90 plays a key role in the occurrence and progression of gastric cancer. However, the molecular mechanism of CD90 in gastric cancer is currently unclear. In order to identify the molecular mechanism by which CD90 affects the biological behavior and energy metabolism of gastric cancer cells, the present study used Cell Counting Kit- 8 assays, lactate concentration determination and ATP content determination. The results demonstrated that CD90 promotes proliferation and inhibits senescence in gastric cancer cells. In addition, CD90 enhanced the invasion and migration abilities
\end{abstract}

Correspondence to: Professor Yanhong Zhou, NHC Key Laboratory of Carcinogenesis, Hunan Cancer Hospital and The Affiliated Cancer Hospital of Xiangya School of Medicine, Central South University, 283 Tongzipo Road, Changsha, Hunan 410013, P.R. China

E-mail: zhouyanhong@csu.edu.cn

Dr Gengqiu Luo, Department of Pathology, Xiangya Hospital, Basic School of Medicine, Central South University, 88 Xiangya Road, Changsha, Hunan 410008, P.R. China

E-mail: luogengqiu@csu.edu.cn

*Contributed equally

Abbreviations: HIF-1, hypoxia inducible factor 1; PDK1, pyruvate dehydrogenase kinase 1; LD, lactic acid; LDH, lactate dehydrogenase

Key words: CD90, gastric cancer, proliferation, energy metabolism, PI3K of AGS gastric cancer cells. Overexpression of CD90 resulted in the accumulation of intracellular lactic acid in AGS cells. CD90 upregulated lactate dehydrogenase levels and increased the NADPH/NADP ${ }^{+}$ratio in AGS cells. CD90 overexpression decreased the ATP concentration in AGS cells. PI3K, PDK1, phosphorylated-AKT-Ser473, HIF-1 $\alpha$, MDM2 and SIRT1 levels were upregulated in CD90-overexpressing AGS cells, compared with AGS cells transfected with the empty vector. In contrast, PTEN, p53, SIRT2, SIRT3 and SIRT6 were downregulated. The results indicate that CD90 affects the biological behavior and levels of energy metabolism of gastric cancer cells by targeting the PI3K/AKT/HIF-1 $\alpha$ signaling pathway.

\section{Introduction}

Gastric cancer (GC) is the third leading cause of cancer-associated death and the fourth most prevalent malignancy worldwide, accounting for $8 \%$ of total cancer incidence and $10 \%$ of cancer-associated deaths. There were 21,320 cases of GC (13,020 men and 8,300 women) and 10,540 patients died from GC in 2012 in the United States (1). Patients with advanced GC have a poor prognosis $(2,3)$. The identification of non-invasive tumor markers that can detect the early stages of cancer, or assess the risk of cancer development in individuals may decrease the mortality rate of GC (4). However, the mechanism underlying GC development is not yet fully understood, and further research is required in order to clarify its pathogenesis and potential molecular targets.

The gene encoding CD90 (also known as THY1 or Thy-1 Cell Surface Antigen), is located on human chromosome 11q23.3, and encodes a glycosylphosphatidylinositol-linked cell surface glycoprotein (5-8). CD90 regulates key biological processes, such as cell apoptosis, migration, adhesion, cell-cell and cell-matrix interactions and T-cell activation (5-8). Furthermore, numerous reports have demonstrated that CD90 has key functions in regulating cell proliferation, angiogenesis and metastasis in cancer (9-11). CD90 is a prognostic marker in certain types of cancer $(12,13)$. CD90 is upregulated in 
GC tissues and modulates the expression levels of osteonectin to inhibit the apoptosis of GC cells (14). However, the precise mechanism underlying the effects of CD90 in GC remains unclear.

Non-cancerous cells produce energy primarily via oxidative phosphorylation in mitochondria. Tumor cells, even under aerobic conditions, generate energy primarily through glycolytic pathways (15). During glycolysis, glucose is converted to lactic acid (LD) $(16,17)$. A large number of intermediate products promote cell proliferation. As a result, glucose consumption increases, leading to anaerobic glycolysis (18). The metabolic rates of glucose, lactate, pyruvate, glutamine and fatty acids in tumor cells are notably higher than those in normal cells. Their complex metabolic properties allow tumor cells to generate ATP, maintaining a balance of redox states, and providing energy for survival, growth and proliferation $(19,20)$. Song et al (21) identified intermediate products of aerobic glycolysis pathways, such as increased expression levels of $\alpha$-ketoglutarate and fumaric acid in cancer tissues, indicating that abnormal changes in glucose metabolism could be used to distinguish between GC cells and normal cells. Similarly, previous studies have demonstrated abnormal glucose metabolism is present in GC cells $(22,23)$.

The present study aimed to investigate the effect of CD90 on biological behaviors, such as proliferation, cell senescence, and invasion and migration ability in GC cells. Changes in LD concentration, lactate dehydrogenase (LDH) levels, ATP concentrations and the NADPH/NADP ${ }^{+}$ratio were assessed following induction of CD90 overexpression in GC cells. The present study also investigated the mechanism underlying the effects of CD90 in GC.

\section{Materials and methods}

Cell culture and transfection. The human GC cell line AGS was acquired from the Chinese Academy Medical Science (Beijing, China). Cells were cultured in Ham's/F-12 (HyClone; Cytiva) with 10\% FBS (Gibco; Thermo Fisher Scientific, Inc.), $100 \mu \mathrm{g} / \mathrm{ml}$ streptomycin and $100 \mathrm{U} / \mathrm{ml}$ penicillin (GE Healthcare Life Sciences), at $37^{\circ} \mathrm{C}$ with $5 \% \mathrm{CO}_{2}$. The coding region of the $\mathrm{CD} 90$ gene was generated via PCR using the following primer pair: 5'-ATACTCGAATGAACC TGGCCATCAGCAT-3' and 5'-GCGGAATTCTCACAG GGACATGAAATCCG-3'. PCR was performed under the following conditions: One cycle for $5 \mathrm{~min}$ at $94^{\circ} \mathrm{C} ; 30$ cycles for $45 \mathrm{sec}$ at $94^{\circ} \mathrm{C}, 45 \mathrm{sec}$ at $55^{\circ} \mathrm{C}$ and $90 \mathrm{sec}$ at $72^{\circ} \mathrm{C}$; and final extension for $10 \mathrm{~min}$ at $72^{\circ} \mathrm{C}$. The fragments were cloned into the TA vector (Promega Corporation) and used to transform E. coli JM109 (Takara Biotechnology Co., Ltd.) according to the manufacturers' instructions. Following selection and propagation, the pure plasmid DNA was prepared using standard methods (24). The DNA fragments (498 bp) were removed from the TA vector using restriction enzyme digestion with $X h o I$ and EcoR1 (Promega Corporation) and then subcloned into the pEGFP-N1 vector. The brief steps are as follows: The pEGFP-N1 vector was also treated with restriction enzyme digestion with XhoI and EcoR1 (Promega Corporation), the linear pEGFP-N1 vector was purified, and then the DNA fragments (498 bp) were linked with it to obtain the pEGFP vector with this DNA fragment. The fusion sequences were verified via DNA sequencing using ABI 3730 (Sigma-Aldrich; Merck KGaA). In order to establish a stable CD90-expressing cell line, plasmid pEGFP-N1/CD90 or control empty vector pEGFP-N1 was transfected into AGS cells using Lipofectamine ${ }^{\circledR} 2000$ (Invitrogen; Thermo Fisher Scientific, Inc.) according to the manufacturer's protocol and as previously described $(14,25,26)$. In order to obtain stable CD90-overexpressing cells, 1,000 $\mu \mathrm{g} / \mathrm{ml} \mathrm{G} 418$ (Sigma-Aldrich; Merck KGaA) was added $48 \mathrm{~h}$ after transfection; this level was sustained for $>14$ days. The maintenance concentration, $500 \mu \mathrm{g} / \mathrm{ml} \mathrm{G} 418$, was used throughout the cell culture. CD90 overexpression was verified using western blotting.

Cell Counting Kit-8 (CCK-8) assay. Cell proliferation was detected using a CCK-8 assay (7 Sea Biotech Co., Ltd.) according to the manufacturer's instructions. Cell suspension (200 $\mu \mathrm{l})$ was seeded in 96-well cell culture plates at a density of 1,000 cells/well and incubated at $37^{\circ} \mathrm{C}$ for 6 days. Cell density was measured every $24 \mathrm{~h}$. A total of $20 \mu \mathrm{l} \mathrm{CCK}-8$ solution was added to each well and incubated for $2 \mathrm{~h}$ at $37^{\circ} \mathrm{C}$. Finally, the absorbance was measured at $450 \mathrm{~nm}$ using a Paradigm Detection System (Beckman Coulter, Inc.).

$\beta$-Galactosidase staining. Cells were washed three times in a 6-well plate with 1X PBS and fixed using $\beta$-galactosidase staining stationary solution (cat. no. C0602; Beyotime Institute of Biotechnology) at room temperature for $15 \mathrm{~min}$. The plate was rinsed twice with $1 \mathrm{X}$ PBS, and $1 \mathrm{ml}$ staining solution $(10 \mu \mathrm{l}$ each of $\beta$-galactosidase staining solution A and $\mathrm{B}, 930 \mu 1 \beta$-galactosidase staining solution $\mathrm{C}$ and $50 \mu \mathrm{l}$ $\mathrm{X}$-gal solution) was added. The plate was incubated overnight at $37^{\circ} \mathrm{C}$ without $\mathrm{CO}_{2}$. Cellular senescence was detected using a Senescence-associated $\beta$-Galactosidase Staining kit (cat. no. C0602; Beyotime Institute of Biotechnology). Images were captured using a light microscope (magnification, x10; cat. no. CKX41; Olympus Corporation). Blue $\beta$-galactosidase positive cells were considered to be senescent.

Cell invasion and migration assays. A Corning Matrigel invasion chamber in 24 -well plates with $8-\mu \mathrm{m}$ pores (Corning Life Sciences) and standard Transwell inserts $(6.5 \mathrm{~mm})$ were used to perform the cell invasion assays. In total, $20 \mu \mathrm{l}$ Matrigel was used for per well. A total of $2.5 \times 10^{4}$ cells were suspended in $500 \mu 1$ of serum-free medium (Hyclone; Cyvita) and added to the top chamber. A total of $750 \mu 1$ Ham's/F-12 growth medium (Hyclone; Cyvita) with 20\% FBS was added to the lower chamber. Cells were then allowed to invade onto the lower surface of the upper chamber following incubation in a humidified incubator with $5 \% \mathrm{CO}_{2}$ at $37^{\circ} \mathrm{C}$, for $48 \mathrm{~h}$. The cells were fixed with $4 \%$ paraformaldehyde for $10 \mathrm{~min}$ at room temperature, and stained with $0.1 \%$ crystal violet at room temperature for $10 \mathrm{~min}$. The cells on the upper surface of the upper chamber were removed using a cotton swab. Images were captured using a light microscope at X100 magnification. Cells were counted from at least five randomly selected fields for each experiment. Falcon Cell Culture Inserts with $8-\mu \mathrm{m}$ pores (Corning Life Sciences) were used to perform cell migration assay using the aforementioned method, but without Matrigel coating on the upper surface of the Transwell filters. 
$L D$ assay. A total of $\sim 5 \times 10^{5}$ cells were seeded and cultured for $48 \mathrm{~h}$ for each group. The LD content in the cells and media were detected. Ultrasonic fragmentation $(40 \mathrm{kHz}$, for $5 \mathrm{sec}$ and stopped for $1 \mathrm{sec}$, on ice) was used to produce the cell homogenate, and reagents were added according to the manufacturer's instructions (Nanjing Jiancheng Bioengineering Institute). Absorbance was measured at $721 \mathrm{~nm}$ using the Paradigm Detection system (Beckman Coulter, Inc.). Finally, the protein concentration was determined to calibrate the LD value in each group.

LDH detection. A total of $\sim 1 \times 10^{6}$ cells were seeded and cultured at $37^{\circ} \mathrm{C}$ for $48 \mathrm{~h}$ for each group. The LDH content in the cells and media were detected. Ultrasonic fragmentation (40 kHz for $5 \mathrm{sec}$ and stopped for $1 \mathrm{sec}$ on ice) was used to produce the cell homogenate, and then reagents were added according to the manufacturer's instructions (Nanjing Jiancheng Bioengineering Institute). Absorbance was measured at $440 \mathrm{~nm}$ using the Paradigm Detection system. Finally, the protein concentration was determined and used to calibrate the LD value in each group.

$N A D P^{+} / N A D P H$ assay. In order to extract $\mathrm{NADP}^{+}$, the Coenzyme II NADP $(\mathrm{H})$ content test kit was used (cat. no. A115-1-1; Nanjing Jiancheng Bioengineering Institute). In total, $1 \mathrm{ml}$ of acidic extract was added to $5,000,000$ cells. Cells were then sonicated (at $40 \%$ for $5 \mathrm{sec}$ and stopped for $1 \mathrm{sec}$ on ice) for $1 \mathrm{~min}$, boiled for $5 \mathrm{~min}$, cooled in an ice bath and centrifuged at $10,000 \mathrm{x}$ g at $4^{\circ} \mathrm{C}$ for $10 \mathrm{~min}$. The supernatant was retained and an equal volume of alkali extract was added to neutralize it. The solution was mixed and centrifuged at $10,000 \mathrm{x} \mathrm{g}$ for $10 \mathrm{~min}$, followed by the addition of 1-7 reagents from the aforementioned kit then mixing. Absorbance was measured at $570 \mathrm{~nm}$. The NADP ${ }^{+}$ content was calculated as: $4.570 \times(\Delta \mathrm{A}-0.062) / \mathrm{Cpr}$, where $\Delta \mathrm{A}$ is the absorbance value of measuring tube-contrast tube absorbance value, and $\mathrm{Cpr}$ is the sample protein concentration. In order to extract NADPH, $1 \mathrm{ml}$ alkali extract was added to $5,000,000$ cells. Cells were sonicated for $1 \mathrm{~min}(40 \mathrm{kHz}$ for $5 \mathrm{sec}$ and stopped for $1 \mathrm{sec}$ on ice), boiled for $5 \mathrm{~min}$, cooled in an ice bath and centrifuged at $10,000 \mathrm{x}$ g at $4^{\circ} \mathrm{C}$ for $10 \mathrm{~min}$. The supernatant was retained, and the same volume of acid extract as the supernatant was added to neutralize it. The solution was mixed and centrifuged at $10,000 \times \mathrm{g} 4^{\circ} \mathrm{C}$ for $10 \mathrm{~min}$, followed by the addition of 1-7 reagents from the aforementioned kit and mixing. Absorbance was measured at $570 \mathrm{~nm}$ as aforementioned. The NADPH content was calculated as: $7.200 \mathrm{x}(\Delta \mathrm{A}-0.072) / \mathrm{Cpr}$, where $\Delta \mathrm{A}$ is the absorbance value of measuring tube-contrast tube absorbance value, and $\mathrm{Cpr}$ is the sample protein concentration.

ATP detection. An ATP content test kit (cat. no. S0026; Beyotime Institute of Biotechnology) was used to detect the ATP content according to the manufacturer's instructions. Relative fluorescence unit values were determined using a Luminometer (Beckman Coulter, Inc.). A standard curve was constructed and the ATP concentration of the sample was calculated. Protein concentrations were then assessed. The concentration of ATP was divided by the protein concentration and the units were converted to $\mathrm{nmol} / \mathrm{mg}$ protein.
Western blotting analysis. CD90-overexpressing AGS cells (AGS-CD90) and control AGS cells (AGS/vector) were lysed in RIPA buffer (CoWin Biosciences), and a bicinchoninic acid kit (Thermo Fisher Scientific, Inc.) was used to determine the protein concentration. A total $50 \mu \mathrm{g}$ sample protein was added to $5 \mathrm{X}$ loading buffer, boiled for $5 \mathrm{~min}$, then separated using 10\% SDS-PAGE gel and transferred onto nitrocellulose membranes (HyClone; Cytiva). The nitrocellulose membranes were incubated at $4^{\circ} \mathrm{C}$ with TBST $((25 \mathrm{mM}$ Tris- $\mathrm{HCl}, 150 \mathrm{mM}$ $\mathrm{NaCl}, \mathrm{pH} 7.5$ and $0.05 \%$ Tween-20) containing 5\% non-fat milk, followed by overnight incubation at $4{ }^{\circ} \mathrm{C}$ with the following primary antibodies: Rabbit anti-CD90, anti-PI3K, anti-PDK1, mouse anti-AKT, rabbit anti-phosphorylated (p)-AKT-Ser473, anti-HIF-1 $\alpha$, mouse anti-MDM2, mouse anti-PTEN, rabbit anti-p53, mouse anti-Sirtuin (SIRT) 1, mouse anti-SIRT 2, rabbit anti-SIRT 3 and mouse anti-SIRT 6 (all 1:1,000; cat.nos. YT0783, YT3709, YT3645, YT0173, YP0006, YT2133, YT2692, YT5752, YT3528, YM1416, YM1271, YT4304 and YM1274, respectively; all ImmunoWay Biotechnology Company). After washing three times with PBS and incubation with labeled secondary antibodies, including anti-rabbit secondary antibody $(1: 3,000$; cat. no. sc-2004) and anti-mouse secondary antibody (1:3,000; cat. no. sc-2005) (both Santa Cruz Biotechnology, Inc.), signals were visualized using an enhanced chemiluminescence detection system (EMD Millipore). Rabbit anti- $\beta$-tubulin (1:5,000; cat. no. T0028; Affinity Biosciences) was used as a loading control.

Statistical analysis. The data are presented as the mean \pm standard error of the mean from three independent experiments. Differences in parametric variables were analyzed using one-way ANOVA followed by Student-Newman-Keuls post hoc test, and differences in non-parametric variables between groups were analyzed by Kruskal-Wallis test followed by Bonferroni's. Differences of non-parametric variables were analyzed using Mann Whitney U tests. Differences between two quantitative variable groups were analyzed using unpaired Student's t-tests and GraphPad Prism version 5.01 (GraphPad Software). All other statistical analyses was performed using SPSS (version 11.0; SPSS, Inc.). $\mathrm{P}<0.05$ was considered to indicate a statistically significant difference.

\section{Results}

CD90 promotes proliferation of GC cells. A previous study demonstrated that expression levels of CD90 are higher in GC tissues compared with adjacent normal tissues (9). In order to investigate the effect and potential mechanism of CD90 in GC, a CD90-overexpressing AGS cell line was established, using G418 to select the positive clones. Western blotting confirmed that CD90 was stably and highly expressed in AGS-CD90 cells (Fig. 1A). In order to verify whether CD90 influences the proliferation rate of GC cells, a CCK-8 assay was performed. The results demonstrated that the cell proliferation rate was significantly increased in AGS-CD90 cells compared with that in control cells $(\mathrm{P}<0.05)$. These results indicated that CD90 promotes proliferation of GC cells (Fig. 1B).

CD90 inhibits senescence of GC cells. Senescence represents stable cell cycle arrest and serves a key role in tumor 
A

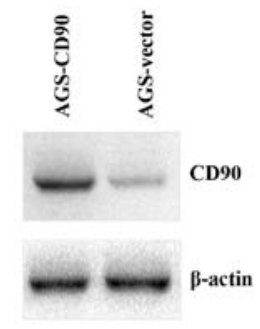

B $1.2 \cdot$ AGS/vector

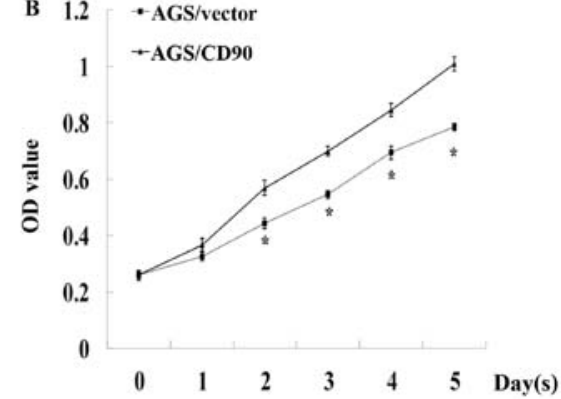

D

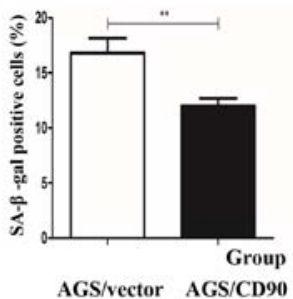

AGS/vector AGS/CD90

C
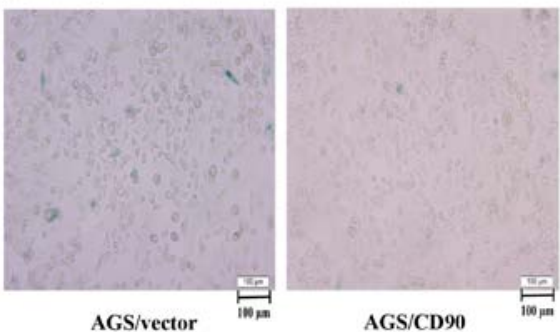

Figure 1. Detection of cell proliferation and senescence in gastric cancer cells. (A) Western blotting analysis of CD90 in AGS-CD90 and AGS-vector cells (B) CCK-8 analysis was performed using a CCK-8 assay kit. (C and D) Cell senescence analysis using $\beta$-galactosidase staining (magnification, $\mathrm{x} 200$ ). Histogram shows the percentage of senescent cells. Data are presented as the mean \pm standard error of the mean. P-values were calculated using Unpaired ${ }^{*} \mathrm{P}<0.05,{ }^{* *} \mathrm{P}<0.01$. AGSCD-90, gastric cancer cells transfected with pEGFP-N1/CD90; AGS-vector, gastric cancer cells transfected with pEGFP-N1; CCK-8, Cell Counting Kit-8.

development and suppression. The senescence-specific marker $\beta$-galactosidase catalyzes the production of a blue-green product of X-Gal, and those cells stained with $\beta$-galactosidase appear blue-green in color when observed under a microscope according to the instructions of the $\beta$-galactosidase staining kit (cat. no. C0602; Beyotime Institute of Biotechnology). The role of CD90 in cell senescence was assessed using $\beta$-galactosidase staining in the present study. The percentage of senescent AGS-CD90 cells was $12.14 \%$, while that in the control group was $17.09 \%$. The proportion of AGS-CD90 cells that were positive for $\beta$-galactosidase staining was significantly smaller than that of the control cells $(\mathrm{P}<0.05)$. This indicated that CD90 inhibits the senescence of AGS cells (Fig. 1C and D).

CD90 promotes the invasion and migration abilities of $G C$ cells. Invasion and migration ability experiments were performed. The results demonstrated that the number of invasive cells in the AGS-CD90 group was 1,397, while that in the control group was 406 . The number of migratory cells in the AGS-CD90 group was 163, whereas that in the control group was 61. The number of AGS-CD90 cells passing through matrix (cell invasion test) or polycarbonate membrane (cell migration test) in the low nutritional environment was higher than that of AGS-vector cells $(\mathrm{P}<0.01)$. These results demonstrated that CD90 promoted the invasion and migration abilities of GC cells (Fig. 2).

CD90 affects the LD concentration of GC cells. LD is a key metabolite in aerobic glycolysis in tumor cells. The level of LD is associated with tumor metastasis and poor prognosis $(27,28)$. LD concentration was detected in AGS-CD90, AGS-vector cells and culture supernatant in the present study. There was no significant difference in the LD concentrations between the AGS-CD90 and AGS-vector cell culture supernatant. However, the intracellular LD concentration of AGS-CD90 cells was higher than that of the AGS-vector cells. These results indicated that CD90 overexpression resulted in the accumulation of LD in GC cells (Fig. 3A and B).

CD90 upregulates LDH concentration in GC cells. Pyruvate is degraded to LD under the action of LDH and cannot enter the tricarboxylic acid cycle (29). Therefore, it was hypothesized that the level of LDH in AGS-CD90 cells would be altered in the present study. LDH concentration was detected in the cells and culture supernatant of the AGS-CD90 and AGS-vector groups. The intracellular LDH concentration was increased in AGS-CD90 cells compared with that in AGS-vector cells. However, there was no significant difference in LDH concentration in the cell culture supernatant of the AGS-CD90 and AGS-vector groups (Fig. 3C and D).

CD90 increases the NADPH/NADP ${ }^{+}$ratio of $G C$ cells. NADP ${ }^{+}$ is a coenzyme of dehydrogenases and produces NADPH. Therefore, changes to the NADPH/NADP ${ }^{+}$ratio are associated with the pentose phosphate pathway and biosynthesis. The present study compared the intracellular NADPH/NADP ${ }^{+}$ ratios of AGS-CD90 and AGS-vector cells. The results demonstrated that the NADPH/NADP ${ }^{+}$ratio in AGS-CD90 cells was higher than that in control cells. The present results also indicated that CD90 influenced levels of NADPH and $\mathrm{NADP}^{+}$in GC cells (Fig. 4A).

CD90 decreases the ATP concentration of GC cells. $\mathrm{NADPH} / \mathrm{NADP}^{+}$is associated with intracellular ATP content. In order to investigate whether CD90 affects the ATP levels of GC cells, ATP concentration was detected in the cells and culture supernatant of the AGS-CD90 and 

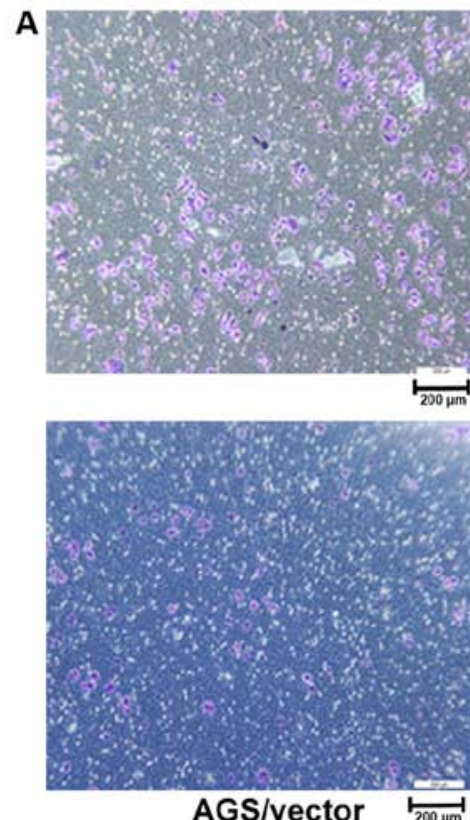

AGS/vector
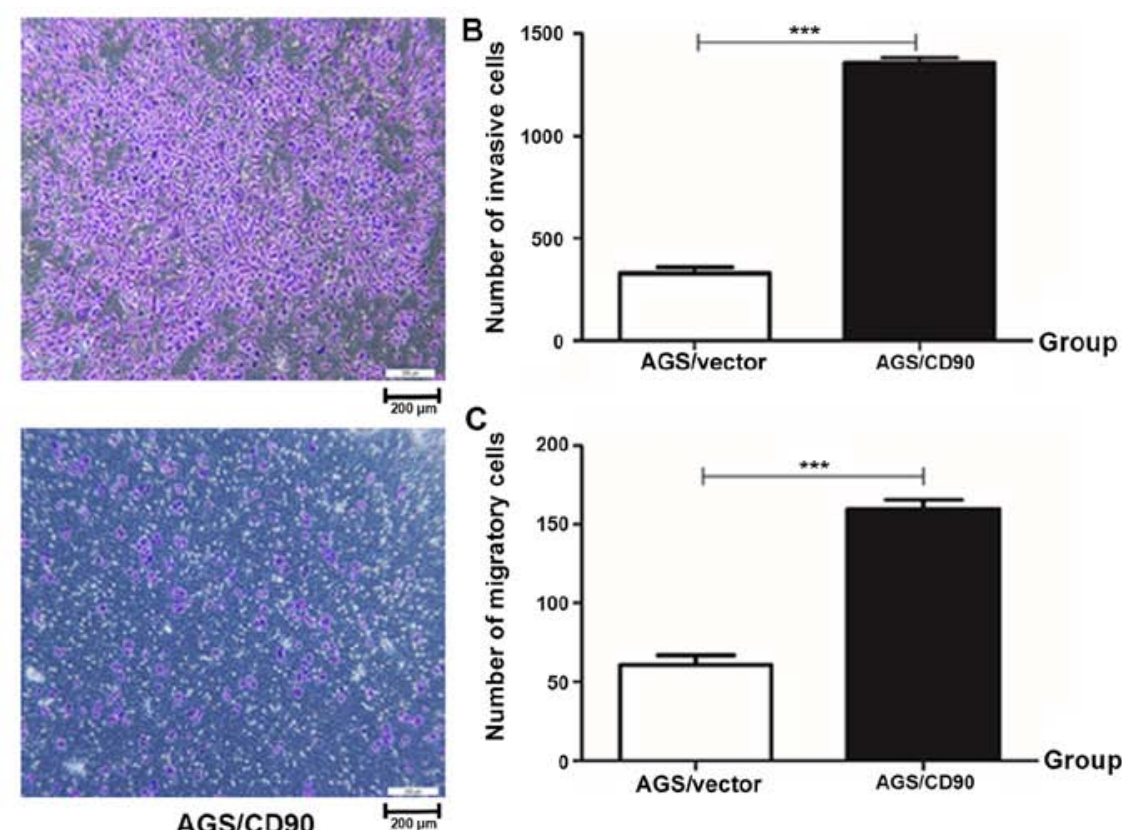

Figure 2. Analysis of invasion and migration ability in gastric cancer cells. (A) Transwell assay of AGS/CD90 and AGS/vector cells. (B and C) Histogram shows the number of invasive and migratory cells. Data are presented as the mean \pm standard error of the mean. P-values were calculated using Unpaired. ${ }^{* * * *} \mathrm{P}<0.001$. AGS/CD90, gastric cancer cells transfected with pEGFP-N1/CD90; AGS/vector, gastric cancer cells transfected with pEGFP-N1.

A

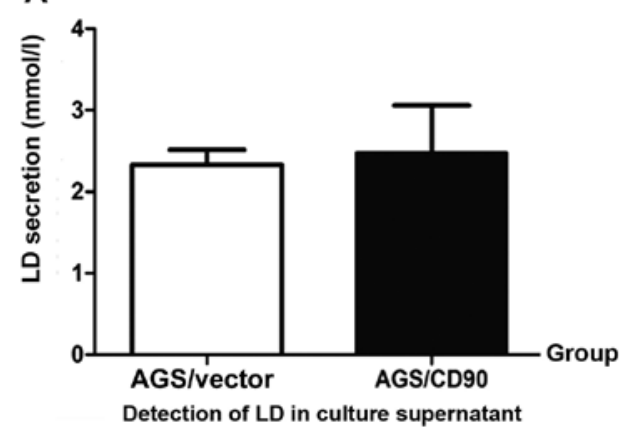

C

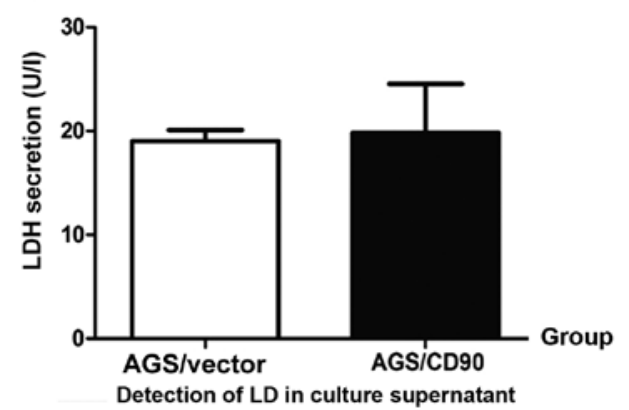

B

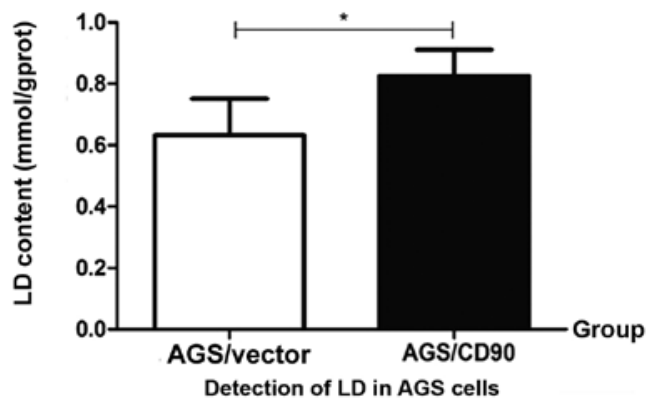

D

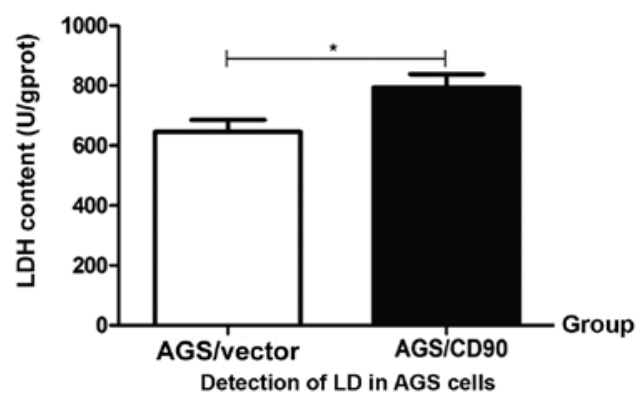

Figure 3. Detection of LD and LDH in gastric cancer cells. (A and B) Levels of LD. (C and D) Activity of LDH. Data are presented as the mean \pm standard error of the mean. P-values were calculated using unpaired Student's t-tests. " $\mathrm{P}<0.05$. LD, lactate; LDH, lactate dehydrogenase; AGS/CD90, gastric cancer cells transfected with pEGFP-N1/CD90; AGS/vector, gastric cancer cells transfected with pEGFP-N1.

AGS-vector groups. The ATP concentration was lower in AGS-CD90 cells compared with that in the AGS-vector cells. This indicated that CD90 decreases ATP concentration in GC cells (Fig. 4B).

CD90 affects the biological behavior and levels of energy metabolism of $G C$ cells by regulating the PI3K/AKT/HIF-1 $\alpha$ signaling pathway. Western blotting was performed to investigate the mechanism by which CD90 affects biological behavior and energy metabolism in GC cells. The results demonstrated that levels of PI3K, PDK1, p-AKT-Ser473, HIF- $1 \alpha$ and MDM2 were upregulated in AGS-CD90 cells compared with control cells. In contrast, levels of PTEN and p53 were downregulated in AGS-CD90 cells (Fig. 5). The 

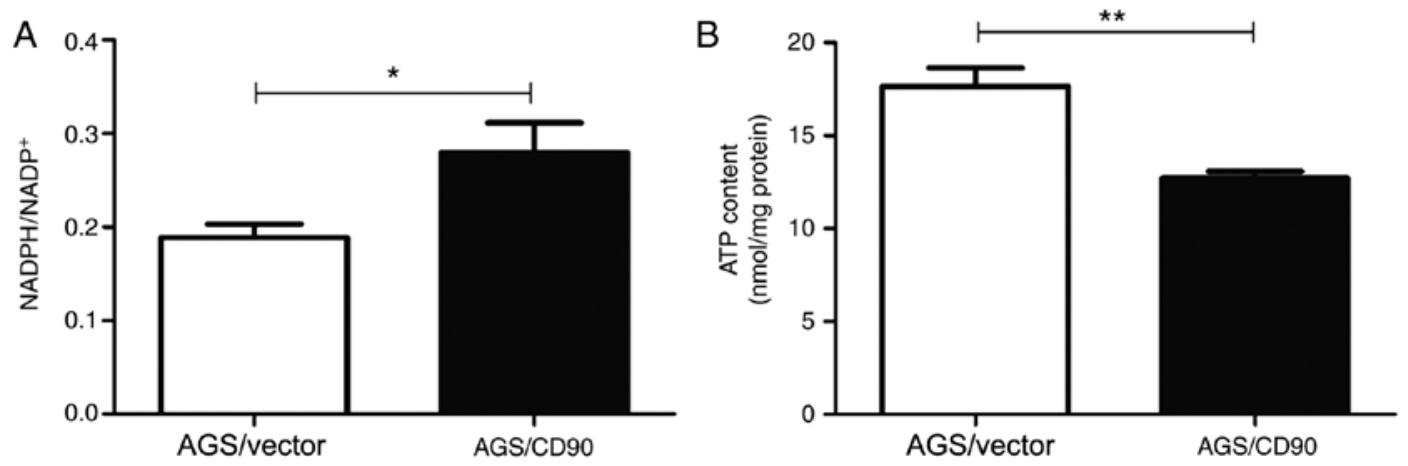

Figure 4. NADPH/NADP ${ }^{+}$ratio and ATP level in gastric cancer cells. (A) NADPH/NADP ${ }^{+}$ratio. (B) Levels of extracellular ATP. ${ }^{*} \mathrm{P}<0.05,{ }^{* *} \mathrm{P}<0.01$. AGS/CD90, gastric cancer cells transfected with pEGFP-N1/CD90; AGS/vector, gastric cancer cells transfected with pEGFP-N1.

A

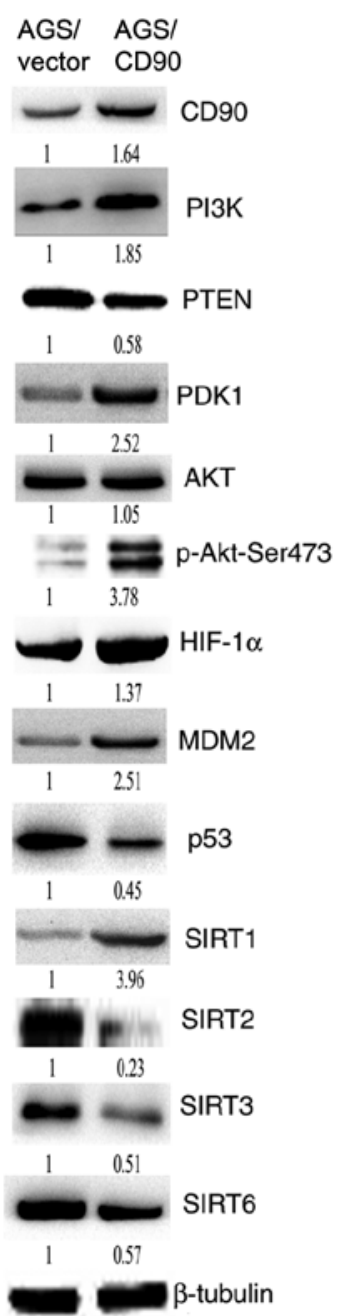

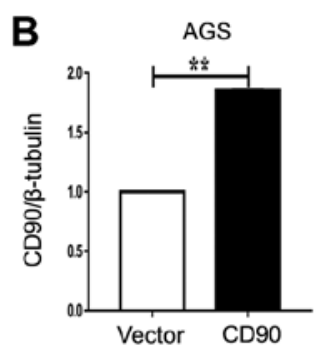
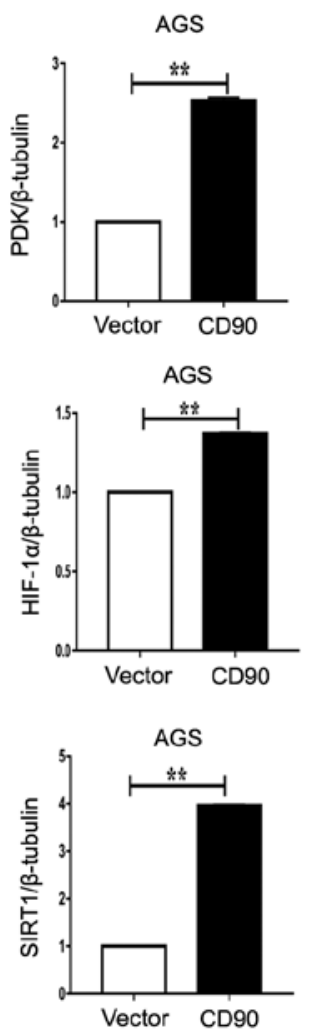
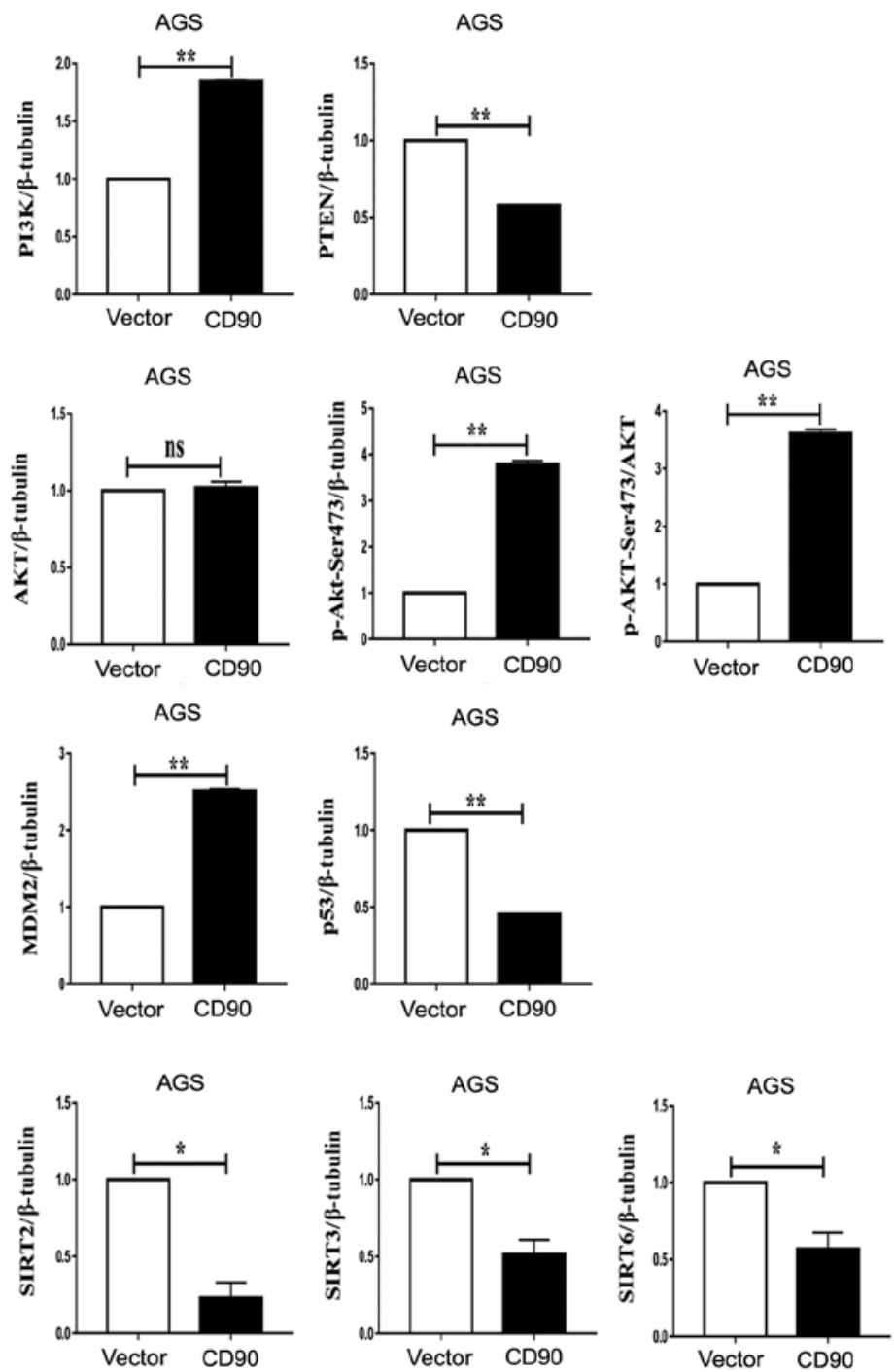

Figure 5. Western blotting analysis of the PI3K/AKT/HIF-1 $\alpha$ signaling pathway. (A) Levels of PI3K, PTEN, PDK1, AKT, p-AKT-Ser473, HIF-1 $\alpha$, MDM2, P53, SIRT2, SIRT3 and SIRT6 were assessed via western blotting. Left, AGS-vector cells; right, AGS-CD90 cells. (B) Densitometric analysis of the western blotting results. ${ }^{*} \mathrm{P}<0.05,{ }^{* *} \mathrm{P}<0.01$. HIF-1 $\alpha$, hypoxia-inducible factor $1 \alpha$; SIRT, Sirtuin; Vector, gastric cancer cells transfected with pEGFP-N1; CD90, gastric cancer cells transfected with pEGFP-N1/CD90.

results of the present study demonstrated that CD90 affects the activity of the PI3K/AKT/HIF-1 $\alpha$ signaling pathway. In addition, expression levels of SIRT1 were upregulated in AGS-CD90 cells compared with control cells. Meanwhile,
SIRT2, SIRT3 and SIRT6 levels were downregulated in AGS-CD90 cells (Fig. 5). These results indicate that CD90 affects the levels of LD and ATP via regulation of levels of SIRTs and HIF-1 $\alpha$. 


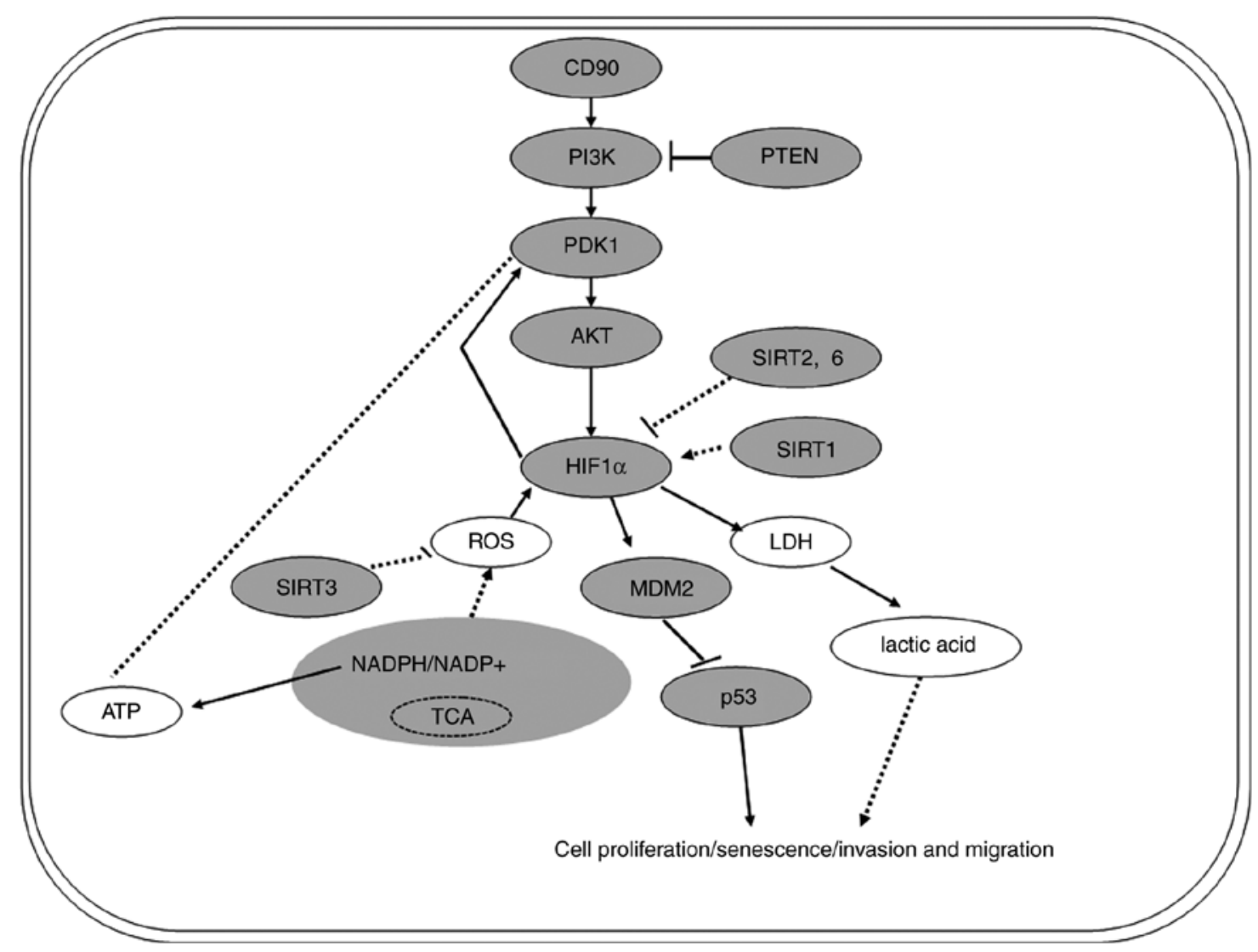

Figure 6. Diagram of the potential signaling pathway by which CD90 regulates biological behavior and energy metabolism in gastric cancer cells. PDK, pyruvate dehydrogenase kinase; SIRT, Sirtuin; HIF, hypoxia-inducible factor; ROS, reactive oxygen species; LDH, lactate dehydrogenase.

\section{Discussion}

GC is the fourth most frequently occurring malignancy worldwide $(1,30)$, and is the second leading cause of cancer-associated mortality (31). East Asia accounts for $\sim 60 \%$ of GC cases worldwide, and $41 \%$ of cases occur in China alone (1). Although progress in early diagnosis and adjuvant therapy has improved outcomes for patients with GC, radical surgery remains to be the primary treatment approach. GC can relapse with local or distant metastasis following radical gastrectomy; therefore, outcomes remain unsatisfactory. The pathogenesis of GC is a multi-factor and multi-step process, involving microorganisms, proto-oncogenes, tumor suppressor genes and immunological factors (32-35). Helicobacter pylori is considered to be a notable cause of GC but does not account for all cases (36). Thus, the molecular basis of GC remains unclear.

Energy metabolism in cancer cells is an area of interest in research. The Warburg effect indicates that cancer cells have faults in mitochondrial oxidative phosphorylation (37). Even in the presence of plentiful oxygen, cancer cells rely primarily on anaerobic glycolysis in the cytosol as a source of ATP to support cell proliferation (38). Normal cells do not tend to use the aerobic glycolysis pathway. Aerobic glycolysis occurs most frequently in proliferative cells, such as tumor cells, which use glucose via the glycolysis pathway, even in aerobic conditions, which requires overexpression of glucose transporters and glycolytic enzymes, resulting in the secretion of LD (39-41).
A previous study verified that abnormally high expression levels of CD90 are present in GC tissues, and as such, constructed an AGS cell line that stably overexpresses CD90, demonstrating that CD90 promotes proliferation and inhibits apoptosis (14). The present study investigated the effect of CD90 on the biological behavior and energy metabolism of GC cells. CD90 promoted cell proliferation and the invasion and migration abilities of AGS cells, and inhibited their senescence. Overexpression of CD90 promoted the accumulation of LD and ATP, upregulated the LDH concentration and increased the intracellular NADPH/NADP ${ }^{+}$ratio in AGS cells. The association between metabolic levels of lactate, ATP and malignant tumors has been confirmed by previous studies (42). For example Choi et al (43) demonstrated that elevated glycolysis, combined with increased LD production and secretion, is a key metabolic feature of neuroendocrine prostate cancer (NEPC). Certain oncogenes or tumor suppressor genes serve key roles in the regulation of metabolism and biological behavior of malignant tumor cells. Monocarboxylate transporter 4 (MCT4) is a plasma membrane LD transporter. The expression level of MCT4 can be inhibited using antisense oligonucleotides; this decreases LD secretion and glucose metabolism, thus affecting the proliferation of NEPC cells (43). Similarly, the present study demonstrated that CD90 serves a key role in the metabolism and biological behavior of GC cells. It has also been demonstrated that LD secreted by tumors is associated with a decrease of macrophages in head and neck squamous cell carcinoma, and induces polarization of M2-like macrophages (44). These previous studies also demonstrate the 
key role of LD in the pathogenesis of malignant tumors. LD, NADPH, ATP and other metabolites serve an important role in the occurrence and progression of malignant tumor cells. Circulating melanoma cells, metastases and primary tumor cells exhibit elevated levels of reactive oxygen species (ROS). Compared with these cells, a highly metastatic type of cancer experiences reversible metabolic changes, increased mitochondrial NADPH levels and ROS stress resistance; inhibition of these effects decreases metastasis of tumor cells $(39,45)$. ATP is released into the extracellular matrix via exocytosis or hemichannels (46). In order to amplify TGF- $\beta 1$-induced migration of lung cancer cells, autocrine signaling via exocytosis of ATP and activation of P2 receptors is required (47). Alvarez et al (48) demonstrated that hemichannels activate the downstream region of the $\alpha \mathrm{V} \beta 3$ integrin-PI3K-PLC $\gamma$-IP3R pathway and are responsible for Thy-1-induced, hemichannel-mediated and Syndecan-4-modulated ATP release, which transactivates $\mathrm{P} 2 \mathrm{X} 7 \mathrm{R}$ s to induce $\mathrm{Ca}(2+)$ entry into cells. The present study demonstrated that CD90 affects the levels of LD, ATP and other metabolites of GC cells, and influences the invasion and metastasis ability of GC cells, thus clarifying the function and mechanism of CD90 in GC.

In order to investigate the mechanism underlying the effects of CD90 on the biological behavior and energy metabolism of GC cells, key molecules involved in the $\mathrm{PI} 3 \mathrm{~K} / \mathrm{AKT} / \mathrm{HIF}-1 \alpha$ signaling pathway were assessed. It was demonstrated that CD90 upregulated the levels of PI3K, PDK1, AKT, p-AKT-Ser473, HIF-1 $\alpha$ and MDM2, and downregulated the levels of PTEN and p53 (Fig. 6).Hyper-activation of PI3K/AKT signaling is common in numerous types of malignant tumor and promotes cell proliferation (49). Studies have demonstrated that metastasis suppressor protein 1 is regulated by PTEN to suppress invasion, migration and epithelial-to-mesenchymal transition of gastric carcinoma cells by inactivating PI3K/AKT signaling $(50,51)$. Dupuy et al (52) demonstrated that pyruvate dehydrogenase kinase 1 phosphorylates pyruvate dehydrogenase, thus serving a key role in reprogramming metabolism. HIF-1 $\alpha$ is another key molecule in the PI3K/AKT/HIF-1 $\alpha$ signaling pathway. Studies have demonstrated that dimerization of the HIF- $1 \alpha$ and $-\beta$ subunits forms the HIF-1 complex $(53,54)$. This complex alters the transcription of associated genes such that tumor cells under hypoxic conditions generate energy to maintain growth $(55,56)$. In tumor cells, mutated p53 cannot interact with BCL2 and therefore cannot promote mitochondrial membrane permeation. Therefore, in addition to the effect on transcriptional activity, the p53 mutant can also promote the survival of cancer cells via direct action on mitochondrial function (57). Furthermore, the Sirtuin histone deacetylase family has been identified as a key regulatory factor in metabolism of cancer cells $(58,59)$. In summary, the PI3K/AKT/HIF-1 $\alpha$ signaling pathway serves a key role in regulating the metabolism and biological behavior of malignant tumor cells (Fig. 6).

The present study demonstrated that CD90 affects the metabolism and biological behavior of GC cells via the $\mathrm{PI} 3 \mathrm{~K} / \mathrm{AKT} / \mathrm{HIF}-1 \alpha$ signaling pathway. The interaction between CD90 and this pathway, and the mechanism underlying its regulation, are not yet fully understood. Further investigations are thus required in order to elucidate this.
The present study demonstrated that CD90 disrupts the biological behavior and metabolic processes of GC cells, potentially via the PI3K/AKT/HIF-1 $\alpha$ signaling pathway.

\section{Acknowledgements}

Not applicable.

\section{Funding}

The present study was supported by the National Natural Sciences Foundation of China (grant no. 81672685) and the Science and Technology Foundation Survey Project of Ministry of Science and Technology of China (grant nos. 2018 FY100900 and 2018FY10090004)

\section{Availability of data and materials}

Not applicable.

\section{Authors' contributions}

LG performed the cell proliferation, invasion and migration experiments, as well as the lactic acid and lactate dehydrogenase experiments. JL performed the cell senescence, $\mathrm{NADPH} / \mathrm{NADP}^{+}$ratio, and ATP concentration experiments. JH, LL and $\mathrm{ZH}$ analyzed the PI3K/AKT/HIF-1 $\alpha$ signaling pathway. CY and XJ also performed the NADPH/NADP ${ }^{+}$ ratio and ATP concentration experiments. GL and $\mathrm{YZ}$ were responsible for the design and writing of the manuscript. All authors read and approved the final manuscript.

\section{Ethics approval and consent to participate}

Not applicable.

\section{Patient consent for publication}

Not applicable.

\section{Competing interests}

The authors declare that they have no competing interests.

\section{References}

1. Siegel R, Naishadham D and Jemal A: Cancer statistics, 2012. CA Cancer J Clin 62: 10-29, 2012.

2. Cunningham D, Allum WH, Stenning SP, Thompson JN, Van de Velde CJ, Nicolson M, Scarffe JH, Lofts FJ, Falk SJ, Iveson TJ, et al: Perioperative chemotherapy versus surgery alone for resectable gastroesophageal cancer. N Engl J 355: 11-20, 2006.

3. Ueda T, Volinia S, Okumura H, Shimizu M, Taccioli C, Rossi S, Alder H, Liu CG, Oue N, Yasui W, et al: Relation between microRNA expression and progression and prognosis of gastric cancer: A microRNA expression analysis. Lancet Oncol 11: 136-146, 2010.

4. Cancer Genome Atlas Research Network: Comprehensive molecular characterization of gastric adenocarcinoma. Nature 513: 202-209, 2014

5. Jeng CJ, McCarroll SA, Martin TF, Floor E, Adams J, Krantz D, Butz S, Edwards R and Schweitzer ES: Thy-1 is a component common to multiple populations of synaptic vesicles. J Cell Biol 140: 685-698, 1998. 
6. Kawamura K, Hiroshima K, Suzuki T, Chai K, Yamaguchi N, Shingyoji M, Yusa T, Tada Y, Takiguchi Y, Tatsumi K, et al: CD90 is a diagnostic marker to differentiate between malignant pleural mesothelioma and lung carcinoma with immunohistochemistry. Am J Clin Pathol 140: 544-549, 2013.

7. Shaikh MV, Kala M and Nivsarkar M: CD90 a potential cancer stem cell marker and a therapeutic target. Cancer Biomark 16: 301-307, 2016

8. Kumar A, Bhanja A, Bhattacharyya $\mathrm{J}$ and Jaganathan BG: Multiple roles of CD90 in cancer. Tumour Biol 37: 11611-11622, 2016.

9. Zhu J, Thakolwiboon S, Liu X, Zhang M and Lubman DM: Overexpression of CD90 (Thy-1) in pancreatic adenocarcinoma present in the tumor microenvironment. PLoS One 9: e115507, 2014.

10. Lung HL, Cheung AK, Cheng Y, Kwong FM, Lo PH, Law EW Chua D, Zabarovsky ER, Wang N, Tsao SW, et al: Functional characterization of THY1 as a tumor suppressor gene with antiinvasive activity in nasopharyngeal carcinoma. Int J Cancer 127: 304-312, 2010.

11. Tang KH, Dai YD, Tong M, Chan YP, Kwan PS, Fu L, Qin YR, Tsao SW, Lung HL, Lung ML, et al: A CD90(+) tumor-initiating cell population with an aggressive signature and metastatic capacity in esophageal cancer. Cancer Res 73: 2322-2332, 2013.

12. Pirozzi G, Tirino V, Camerlingo R, La Rocca A, Martucci N, Scognamiglio G, Franco R, Cantile M, Normanno N and Rocco G Prognostic value of cancer stem cells, epithelial-mesenchymal transition and circulating tumor cells in lung cancer. Oncol Rep 29: 1763-1768, 2013.

13. Lu JW, Chang JG, Yeh KT, Chen RM, Tsai JJ and Hu RM: Overexpression of Thy1/CD90 in human hepatocellular carcinoma is associated with HBV infection and poor prognosis. Acta Histochem 113: 833-838, 2011.

14. Zhu GC, Gao L, He J, Long Y, Liao S, Wang H, Li X, Yi W, Pei Z, Wu M, et al: CD90 is upregulated in gastric cancer tissues and inhibits gastric cancer cell apoptosis by modulating the expression level of SPARC protein. Oncol Rep 34: 2497-2506, 2015.

15. Martinez-Outschoorn UE, Peiris-Pagés M, Pestell RG, Sotgia F and Lisanti MP: Cancer metabolism: A therapeutic perspective. Nat Rev Clin Oncol 14: 113, 2017.

16. Koppenol WH, Bounds PL and Dang CV: Otto Warburg's contributions to current concepts of cancer metabolism. Nat Rev Cancer 11: 325-337, 2011

17. Le A, Cooper CR, Gouw AM, Dinavahi R, Maitra A, Deck LM, Royer RE, Vander Jagt DL, Semenza GL and Dang CV: Inhibition of lactate dehydrogenase A induces oxidative stress and inhibits tumor progression. Proc Natl Acad Sci USA 107: 2037-2042, 2010.

18. Cairns RA, Harris IS and Mak TW: Regulation of cancer cell metabolism. Nat Rev Cancer 11: 85-95, 2011.

19. Doherty JR and Cleveland JL: Targeting lactate metabolism for cancer therapeutics. J Clin Invest 123: 3685-3692, 2013.

20. Yuan LW, Yamashita H and Seto Y: Glucose metabolism in gastric cancer: The cutting-edge. World J Gastroenterol 22 2046-2059, 2016.

21. Song H, Wang L, Liu HL, Wu XB, Wang HS, Liu ZH, Li Y, Diao DC, Chen HL and Peng JS: Tissue metabolomic fingerprinting reveals metabolic disorders associated with human gastric cancer morbidity. Oncol Rep 26: 431-438, 2011.

22. Wu H, Xue R, Tang Z, Deng C, Liu T, Zeng H, Sun Y and Shen X: Metabolomic investigation of gastric cancer tissue using gas chromatography/mass spectrometry. Anal Bioanal Chem 396 : $1385-1395,2010$

23. Cai Z, Zhao JS, Li JJ, Peng DN, Wang XY, Chen TL, Qiu YP, Chen PP, Li WJ, Xu LY, et al: A combined proteomics and metabolomics profiling of gastric cardia cancer reveals characteristic dysregulations in glucose metabolism. Mol Cell Proteomics 9: $2617-2628,2010$

24. Sambrook J and Russell DW: Molecular Cloning: A Laboratory Manual. 3rd edition. Cold Spring Harbor Laboratory Press, New York, NY, 2001.

25. He J, Zhu G, Gao L, Chen P, Long Y, Liao S, Yi H, Yi W, Pei Z, $\mathrm{Wu} \mathrm{M}$, et al: Fra-1 is upregulated in gastric cancer tissues and affects the PI3K/Akt and $\mathrm{p} 53$ signaling pathway in gastric cancer. Int J Oncol 47: 1725-1734, 2015.

26. Liao S, Xiao S, Zhu G, Zheng D, He J, Pei Z, Li G and Zhou Y: CD38 is highly expressed and affects the PI3K/Akt signaling pathway in cervical cancer. Oncol Rep 32: 2703-2709, 2014.
27. Baumann F, Leukel P, Doerfelt A, Beier CP, Dettmer K, Oefner PJ, Kastenberger M, Kreutz M, Nickl-Jockschat T, Bogdahn U, et al: Lactate promotes glioma migration by TGF-beta2-dependent regulation of matrix metalloproteinase-2. Neuro Oncol 11: 368-380, 2009.

28. Yokota H, Guo J, Matoba M, Higashi K, Tonami H and Nagao Y: Lactate, choline, and creatine levels measured by vitro $1 \mathrm{H}-\mathrm{MRS}$ as prognostic parameters in patients with non-small-cell lung cancer. J Magn Reson Imaging 25: 992-999, 2007.

29. Warburg OH: The classic: The chemical constitution of respiration ferment. Clin Orthop Relat Res 468: 2833-2839, 2010.

30. Kamangar F, Dores GM and Anderson WF: Patterns of cancer incidence, mortality, and prevalence across five continents: Defining priorities to reduce cancer disparities in different geographic regions of the world. J Clin Oncol 24: 2137-2150, 2006.

31. Jemal A, Siegel R, Xu J and Ward E: Cancer statistics, 2010. CA Cancer J Clin 60: 277-300, 2010.

32. Jin EH, Sung JK, Lee SI and Hong JH: Mitochondrial NADH dehydrogenase subunit 3 (MTND3) polymorphisms are associated with gastric cancer susceptibility. Int J Med Sci 15 1329-1333, 2018

33. Buglioni S, Melucci E, Sperati F, Pallocca M, Terrenato I, De Nicola F, Goeman F, Casini B, Amoreo CA, Gallo E, et al: The clinical significance of PD-L1 in advanced gastric cancer is dependent on ARID1A mutations and ATM expression. Oncoimmunology 7: e1457602, 2018.

34. Malfertheiner P: Helicobacter pylori treatment for gastric cancer prevention. N Engl J Med 378: 1154-1156, 2018.

35. Pormohammad A, Ghotaslou R, Leylabadlo HE, Nasiri MJ, Dabiri $\mathrm{H}$ and Hashemi A: Risk of gastric cancer in association with Helicobacter pylori different virulence factors: A systematic review and meta-analysis. Microb Pathog 118: 214-219, 2018.

36. Infection with Helicobacter pylori. IARC Monogr Eval Carcinog Risks Hum 61: 177-240, 1994.

37. Ma B, Cheng H, Mu C, Geng G, Zhao T, Luo Q, Ma K, Chang R, Liu Q, Gao R, et al: The SIAH2-NRF1 axis spatially regulates tumor microenvironment remodeling for tumor progression. Nat Commun 10: 1034, 2019.

38. Warburg O: On the origin of cancer cells. Science 123: 309-314, 1956.

39. Vander Heiden MG and Deberardinis RJ: Understanding the intersections between metabolism and cancer biology. Cell 168: 657-669, 2017.

40. Altman BJ, Stine ZE and Dang CV: From Krebs to clinic: Glutamine metabolism to cancer therapy. Nat Rev Cancer 16: 619-634, 2016.

41. Vander Heiden MG, Cantley LC and Thompson CB: Understanding the warburg effect: The metabolic requirements of cell proliferation. Science 324: 1029-1033, 2009.

42. Hu LP, Zhang XX, Jiang SH, Tao LY, Li Q, Zhu LL, Yang MW, Huo YM, Jiang YS, Tian GA, et al: Targeting purinergic receptor P2Y2 prevents the growth of pancreatic ductal adenocarcinoma by inhibiting cancer cell glycolysis. Clin Cancer Res 25: 1318-1330, 2019.

43. Choi SYC, Ettinger SL, Lin D, Xue H, Ci X, Nabavi N, Bell RH, Mo F, Gout PW, Fleshner NE, et al: Targeting MCT4 to reduce lactic acid secretion and glycolysis for treatment of neuroendocrine prostate cancer. Cancer Med 7: 3385-3392, 2018.

44. Ohashi T, Aoki M, Tomita H, Akazawa T, Sato K, Kuze B, Mizuta K, Hara A, Nagaoka H, Inoue N and Ito Y: M2-like macrophage polarization in high lactic acid-producing head and neck cancer. Cancer Sci 108: 1128-1134, 2017.

45. Piskounova E, Agathocleous $M$, Murphy MM, Hu Z, HuddlestunSE,ZhaoZ,Leitch AM,Johnson TM,DeBerardinis RJ and Morrison SJ: Oxidative stress inhibits distant metastasis by human melanoma cells. Nature 527: 186-191, 2015.

46. Fang WG and Tian XX: Identification of a new pro-invasion factor in tumor microenvironment: Progress in function and mechanism of extracellular ATP. Beijing Da Xue Xue Bao Yi Xue Ban 49: 188-195, 2017 (In Chinese).

47. Takai E, Tsukimoto M, Harada H, Sawada K, Moriyama Y and Kojima S: Autocrine regulation of TGF-betal-induced cell migration by exocytosis of ATP and activation of $\mathrm{P} 2$ receptors in human lung cancer cells. J Cell Sci 125: 5051-5060, 2012.

48. Alvarez A,Lagos-Cabre R, Kong M, Cárdenas A,Burgos-Bravo F, Schneider P, Quest AF and Leyton L: Integrin-mediated transactivation of P2X7R via hemichannel-dependent ATP release stimulates astrocyte migration. Biochim Biophys Acta 1863: 2175-2188, 2016 
49. Yao H, Su S, Xia D, Wang M, Li Z, Chen W, Ren L and Xu L: F-box and leucine-rich repeat protein 5 promotes colon cancer progression by modulating PTEN/PI3K/AKT signaling pathway. Biomed Pharmacother 107: 1712-1719, 2018.

50. Wang H, Zhao Y, Cao L, Zhang J, Wang Y and Xu M: Metastasis suppressor protein 1 regulated by PTEN suppresses invasion, migration, and EMT of gastric carcinoma by inactivating PI3K/AKT signaling. J Cell Biochem 120: 3447-3454, 2019.

51. Matsuoka T and Yashiro M: The role of PI3K/Akt/mTOR signaling in gastric carcinoma. Cancers (Basel) 6: 1441-1463, 2014.

52. Dupuy F, Tabariès S, Andrzejewski S, Dong Z, Blagih J, Annis MG, Omeroglu A, Gao D, Leung S, Amir E, et al: PDK1-dependent metabolic reprogramming dictates metastatic potential in breast cancer. Cell Metab 22: 577-589, 2015.

53. Semenza GL and Wang GL: A nuclear factor induced by hypoxia via de novo protein synthesis binds to the human erythropoietin gene enhancer at a site required for transcriptional activation. Mol Cell Biol 12: 5447-5454, 1992.

54. Wang GL and Semenza GL: Purification and characterization of hypoxia-inducible factor 1. J Biol Chem 270: 1230-1237, 1995.
55. Sáenz-de-Santa-María I, Bernardo-Castiñeira C, Secades P, Bernaldo-de-Quirós S, Rodrigo JP, Astudillo A and Chiara MD: Clinically relevant HIF-1 $\alpha$-dependent metabolic reprogramming in oropharyngeal squamous cell carcinomas includes coordinated activation of CAIX and the miR-210/ISCU signaling axis, but not MCT1 and MCT4 upregulation. Oncotarget 8: 13730-13746, 2017.

56. Devignes CS, Aslan Y, Brenot A, Devillers A, Schepers K, Fabre S, Chou J, Casbon AJ, Werb Z and Provot S: HIF signaling in osteoblast-lineage cells promotes systemic breast cancer growth and metastasis in mice. Proc Natl Acad Sci USA 115: E992-E1001, 2018.

57. Vyas S, Zaganjor E and Haigis MC: Mitochondria and Cancer. Cell 166: 555-566, 2016.

58. Bringman-Rodenbarger LR, Guo AH, Lyssiotis CA and Lombard DB: Emerging roles for SIRT5 in metabolism and cancer. Antioxid Redox Signal 28: 677-690, 2018.

59. De Matteis S, Granato AM, Napolitano R, Molinari C, Valgiusti M, Santini D, Foschi FG, Ercolani G, Vespasiani Gentilucci U, Faloppi L, et al: Interplay between SIRT-3, metabolism and its tumor suppressor role in hepatocellular carcinoma. Dig Dis Sci 62: 1872-1880, 2017. 